\title{
Association of vitamin $D$ receptor gene variants with polycystic ovary syndrome: a meta-analysis
}

\author{
Xiao-Yuan Shi ${ }^{1}$, Ai-Ping Huang ${ }^{2}$, Duo-Wen $X^{3} e^{3}$ and Xiao-Long Yu ${ }^{4 *}$
}

\begin{abstract}
Background: Polycystic ovary syndrome (PCOS) is a common endocrine disorder in reproductive-age women. Multiple susceptible gene as well as environmental factors and their interaction each other are contributed to the PCOS risk. Several case-control studies have researched the associations of the vitamin D receptor gene (VDR) polymorphisms with PCOS susceptibility, but the jury is still out. Here, we carried out a meta-analysis to clarify polymorphisms between Apal (C/A) (rs7975232), Bsml (G/A) (rs 1544410), Fokl (C/T) (rs 10735810), Taql (T/C) (rs731236) and Tru9l (G/A) (rs757343) in the VDR gene and PCOS susceptibility based on relative lager sample size.

Methods: English database of PubMed and Embase, and Chinese database of Wanfang and China National Knowledge Infrastructure (CNKI) databases were retrivaled for the relationship between VDR gene variates and PCOS susceptibility published before 31th, May 2018. Crude odds ratios (ORs) and its 95\% confidence intervals $(95 \% \mathrm{Cls})$ in different comparisons were used to detected the strength of the association. All the statistical analyses of the present meta-analysis were performed by STATA version 12.0 software.

Results: Totally, 3587 (PCOS group 1922; control group 1665) participants from 13 studies were included which met our inclusion criteria. A statistically significant association between VDR Apal (rs7975232) polymorphism and PCOS susceptibility ( $C$ vs. $A: O R=1.19,95 \% \mathrm{Cl}=1.06 \sim 1.34, P=0.004$ ) was found in the overall population. After stratified by ethnicity, we showed that there is a significant association between VDR Apal (rs7975232) polymorphism and susceptibility to PCOS in the Asian ( $\mathrm{C}$ vs. A: $\mathrm{OR}=1.21,95 \% \mathrm{Cl}=1.04 \sim 1.42, \mathrm{P}=0.016$ ) population, but this association was not found in the Caucasian population. Additionally, a significant relationship between VDR Bsml (rs 1544410) variates with PCOS susceptibility in the Asian ( $G$ vs. A: $O R=1.27,95 \% \mathrm{Cl}=1.06 \sim 1.53, P=0.011$ ) population, but this association was not found in the Caucasian population. We didn't find any association between VDR Fokl (rs2228570), VDR Taql (rs731236), VDR Tru9l (rs757343) and PCOS susceptibility in the overall and the subgroup populations.
\end{abstract}

Conclusions: Our findings demonstrated that VDR Apal (rs7975232) and VDR Bsml (rs1544410) polymorphisms are correlated with susceptibility to PCOS in the Asian population and VDR Taql (rs731236), VDR Fokl (rs2228570), VDR Tru9l (rs757343) did not reveal a relationship with the PCOS susceptibility.

Keywords: Polycystic ovary syndrome, Vitamin D receptor, Polymorphisms, Meta-analysis

\footnotetext{
* Correspondence: yxlzjh@sina.com

${ }^{4}$ Zhejiang Hospital, Department of nutrition, Hangzhou 310013, Zhejiang

Province, China

Full list of author information is available at the end of the article
}

(c) The Author(s). 2019 Open Access This article is distributed under the terms of the Creative Commons Attribution 4.0 International License (http://creativecommons.org/licenses/by/4.0/), which permits unrestricted use, distribution, and reproduction in any medium, provided you give appropriate credit to the original author(s) and the source, provide a link to the Creative Commons license, and indicate if changes were made. The Creative Commons Public Domain Dedication waiver (http://creativecommons.org/publicdomain/zero/1.0/) applies to the data made available in this article, unless otherwise stated. 


\section{Background}

A common endocrine syndrome, polycystic ovary syndrome (PCOS), is characterized by long-term absence of ovulation and high androgen, which is the most common causes of menstrual disorders and infertility in women during reproductive years $[1,2]$. The main clinical manifestations of PCOS include abnormal menstruation, ovulation disorder and infertility, hirsutism and acne [3]. In addition to the menstrual disturbance and hyperandrogenism, PCOS patients demonstrate an increased prevalence of type 2 diabetes mellitus, impaired glucose tolerance, hyperinsulinemia, insulin resistance (IR), and obesity $[4,5]$. The underlying causes of PCOS are not completely known. However, being a complex heterogeneous disease, genetic and environmental factors interact with each other in polycystic ovary syndrome play an vital role in the occurrence and development of the disease [6].

IR and hyperinsulinemia are frequent metabolic abnormalities in the PCOS, evidence suggests that vitamin D levels may be linked to hormonal and metabolic disorders [7]. As a steroid hormone, vitamin D could module calcium-phosphate (Ca-P) homeostasis by its conversion into the active hormone 1,25-dihydroxycholecalciferol in the kidneys and liver, and regulate the secretion of insulin through the role on the $\beta$-cells $[8,9]$. The function of vitamin $\mathrm{D}$ is mediated by vitamin $\mathrm{D}$ receptor (VDR), a ligand-dependent transcription factor in the steroid/ thyroid hormone receptor superfamily that controls the pleiotropic biological effects of vitamin D [10-12]. VDR regulates about $3 \%$ of the human genome, including genes critical to glucose metabolism, but the mechanism by which VDR regulates gene expression is unclear [13].

The VDR gene is located on chromosome 12cenq12 and contains 14 exons. Several single nucleotide polymorphisms (SNPs) in the VDR gene have been reported, such as ApaI in intron 8 (C/A) (rs7975232), BsmI in intron 8 (G/A) (rs1544410), FokI in exon 2 (C/T) (rs10735810), TaqI in exon 9 (T/C) (rs731236) and Tru9I in intron 8 (G/A) (rs757343). It has been shown that VDR polymorphisms (ApaI, BsmI, FokI, Tru9I and TaqI) may contribute to the PCOS susceptibility, although the findings are as yet inconclusive [14-26]. A previous meta-analysis has reported the association of $V D R$ gene polymorphism with incident PCOS outcomes, but only six studies were included for analysis [27]. Currently, we performed an updated systematic review and meta-analysis to more

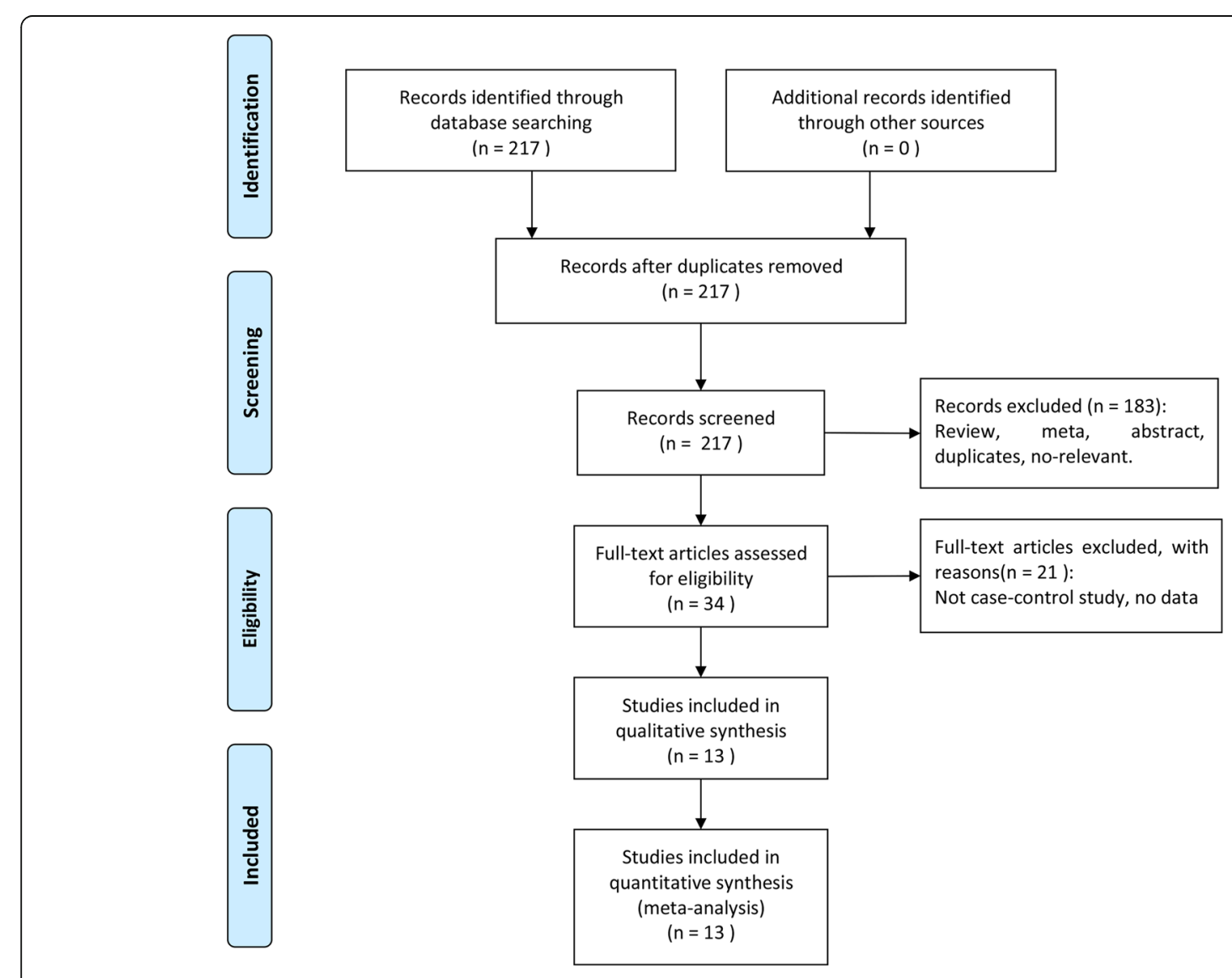

Fig. 1 Flow chart of the literature retrieval and selection process 
Table 1 Characteristics of studies on VDR Apal rs7975232 (A > C) variant and polycystic ovarian syndrome (PCOS) susceptibility

\begin{tabular}{|c|c|c|c|c|c|c|c|c|c|c|c|c|}
\hline \multirow[t]{2}{*}{ Author } & \multirow[t]{2}{*}{ Year } & \multirow[t]{2}{*}{ Country } & \multirow[t]{2}{*}{ Ethnicity } & \multirow{2}{*}{$\begin{array}{l}\text { NOS } \\
\text { scores }\end{array}$} & \multicolumn{2}{|c|}{ Sample size } & \multicolumn{3}{|c|}{ Genotype in cases } & \multicolumn{3}{|c|}{ Genotype in controls } \\
\hline & & & & & PCOS & Control & CC & $A C$ & AA & $\mathrm{CC}$ & $A C$ & AA \\
\hline Dasgupta [14] & 2015 & India & Asian & 7 & 250 & 250 & 13 & 120 & 117 & 13 & 117 & 120 \\
\hline Jedrzejuk [15] & 2015 & Poland & Caucasian & 7 & 90 & 98 & 19 & 52 & 19 & 17 & 49 & 32 \\
\hline Mahmoudi [16] & 2015 & Iran & Asian & 8 & 35 & 35 & 9 & 11 & 15 & 6 & 21 & 8 \\
\hline Mahmoudi [17] & 2009 & Iran & Asian & 8 & 162 & 162 & 36 & 68 & 58 & 23 & 90 & 49 \\
\hline El-Shal [18] & 2013 & Egypt & Caucasian & 8 & 150 & 150 & 22 & 65 & 63 & 18 & 64 & 68 \\
\hline Siddamalla [19] & 2017 & India & Asian & 7 & 95 & 130 & 32 & 21 & 42 & 25 & 35 & 70 \\
\hline Wehr [20] & 2011 & Australia & Caucasian & 7 & 543 & 145 & 127 & 274 & 142 & 37 & 60 & 48 \\
\hline Cao [21] & 2016 & China & Asian & 7 & 120 & 120 & 40 & 58 & 22 & 26 & 55 & 39 \\
\hline Santos [22] & 2018 & Brazil & Caucasian & 7 & 190 & 100 & 41 & 88 & 61 & 16 & 48 & 36 \\
\hline
\end{tabular}

precisely evaluate the correlation between the $V D R$ gene polymorphisms and PCOS susceptibility.

\section{Methods}

Identification of eligible studies

PubMed, EMBASE, Chinese Wanfang, China National Knowledge Infrastructure (CNKI) and other databases were searched. The retrieval period is from establishment to May 31, 2018. The search terms and keywords are as follows: "vitamin D receptor or VDR", "polymorphisms or variants", and "polycystic ovarian syndrome or PCOS". References to retrieved papers were also manually searched for other potential studies not included in the database.

\section{Inclusion and exclusion criteria}

If the study met the following criteria, it was included in the meta-analysis: (1) study on the association of VDR gene with PCOS; (2) case-control study design; (3) genotype distributions were available for both cases and controls to calculate an OR and its 95\%CI; (4) The diagnosis of PCOS is based on the Rotterdam criteria and the National Institute of Child Health and Human Development criteria [28, 29]. Exclusion criteria are as follows: (1) abstract, case report, editorial comment, and review;
(2) repeated publication; (3) studies with insufficient genotypic data; (4) studies performed on animal models.

\section{Quality score assessment}

The quality of the study was assessed using the Newcastle-Ottawa scale. The scale is composed of three aspects: selection, comparability and exposure, with a maximum score of 9 [30]. A total score for each study of $\leq 3,4-6, \geq 7$ is considered to be low, medium and high quality study, respectively. Any disagreements were adjusted by a third reviewer.

\section{Data extraction}

Two researchers independently and carefully extracted the available data from each eligible study. Information on all eligible studies is as follows: (1) surname of the fist author; (2) publication year; (3) country of origin; (4) the ethnicity of population; (5) sample size of cases and controls. Our research team addressed the differences through discussion.

\section{Statistical analysis}

The effect sizes of the association between the $V D R$ gene polymorphisms and PCOS risk were calculated using odds ratios (ORs) and its $95 \%$ confience interval

Table 2 Characteristics of studies on VDR Bsml rs1544410 (A > G) variant and polycystic ovarian syndrome (PCOS) susceptibility

\begin{tabular}{|c|c|c|c|c|c|c|c|c|c|c|c|c|}
\hline \multirow[t]{2}{*}{ Author } & \multirow[t]{2}{*}{ Year } & \multirow[t]{2}{*}{ Country } & \multirow[t]{2}{*}{ Ethnicity } & \multirow{2}{*}{$\begin{array}{l}\text { NOS } \\
\text { scores }\end{array}$} & \multicolumn{2}{|c|}{ Sample size } & \multicolumn{3}{|c|}{ Genotype in cases } & \multicolumn{3}{|c|}{ Genotype in controls } \\
\hline & & & & & $\overline{P C O S}$ & $\overline{\text { Control }}$ & $\overline{\mathrm{GG}}$ & $A G$ & $\mathrm{AA}$ & $\overline{\mathrm{GG}}$ & $A G$ & AA \\
\hline Jedrzejuk [15] & 2015 & Poland & Caucasian & 7 & 90 & 98 & 31 & 45 & 14 & 43 & 42 & 13 \\
\hline Mahmoudi [16] & 2015 & Iran & Asian & 8 & 35 & 35 & 13 & 12 & 10 & 7 & 23 & 5 \\
\hline Mahmoudi [17] & 2009 & Iran & Asian & 8 & 162 & 162 & 53 & 85 & 24 & 53 & 91 & 18 \\
\hline Bagheri [23] & 2012 & Iran & Asian & 7 & 46 & 46 & 4 & 27 & 15 & 2 & 24 & 20 \\
\hline Siddamalla [19] & 2017 & India & Asian & 7 & 94 & 130 & 34 & 45 & 15 & 17 & 41 & 72 \\
\hline Wehr [20] & 2011 & Australia & Caucasian & 7 & 537 & 137 & 77 & 244 & 216 & 49 & 66 & 22 \\
\hline Cao [21] & 2016 & China & Asian & 7 & 120 & 120 & 37 & 60 & 23 & 25 & 55 & 40 \\
\hline Santos [22] & 2018 & Brazil & Caucasian & 7 & 187 & 100 & 74 & 76 & 37 & 41 & 48 & 11 \\
\hline
\end{tabular}


Table 3 Characteristics of studies on VDR Taql rs731236 (T/C) variant and polycystic ovarian syndrome (PCOS) susceptibility

\begin{tabular}{|c|c|c|c|c|c|c|c|c|c|c|c|c|}
\hline \multirow[t]{2}{*}{ Author } & \multirow[t]{2}{*}{ Year } & \multirow[t]{2}{*}{ Country } & \multirow[t]{2}{*}{ Ethnicity } & \multirow{2}{*}{$\begin{array}{l}\text { NOS } \\
\text { scores }\end{array}$} & \multicolumn{2}{|c|}{ Sample size } & \multicolumn{3}{|c|}{ Genotype in cases } & \multicolumn{3}{|c|}{ Genotype in controls } \\
\hline & & & & & PCOS & Control & $\mathrm{CC}$ & $C T$ & $\pi$ & CC & $C T$ & $\pi$ \\
\hline Dasgupta [14] & 2015 & India & Asian & 7 & 252 & 401 & 47 & 92 & 113 & 105 & 110 & 186 \\
\hline Jedrzejuk [15] & 2015 & Poland & Caucasian & 7 & 90 & 98 & 8 & 45 & 37 & 12 & 37 & 49 \\
\hline Mahmoudi [16] & 2015 & Iran & Asian & 8 & 35 & 35 & 6 & 14 & 15 & 4 & 16 & 15 \\
\hline Mahmoudi [17] & 2009 & Iran & Asian & 8 & 162 & 162 & 20 & 71 & 71 & 14 & 76 & 72 \\
\hline El-Shal [18] & 2013 & Egypt & Caucasian & 8 & 150 & 150 & 36 & 74 & 40 & 20 & 61 & 69 \\
\hline Siddamalla [19] & 2017 & India & Asian & 7 & 95 & 130 & 24 & 31 & 40 & 17 & 42 & 71 \\
\hline Bagheri [24] & 2013 & Iran & Asian & 7 & 38 & 38 & 8 & 14 & 16 & 2 & 19 & 17 \\
\hline Wehr [20] & 2011 & Australia & Caucasian & 7 & 536 & 137 & 72 & 238 & 226 & 23 & 65 & 49 \\
\hline Cao [21] & 2016 & China & Asian & 7 & 120 & 120 & 11 & 52 & 57 & 8 & 72 & 40 \\
\hline Santos [22] & 2018 & Brazil & Caucasian & 7 & 188 & 99 & 70 & 87 & 31 & 40 & 48 & 11 \\
\hline
\end{tabular}

(95\%CI). All analyses used the allelic, recessive, and dominant genetic models. The chi-square test based on $\mathrm{Q}$ statistics was used to analyze the inter-study heterogeneity, which was considered to be significant when $p$ value $<0.10$ [31]. Heterogeneity was quantified by $\mathrm{I}^{2}$ test. When $\mathrm{I}^{2}$ was less than $50 \%$, heterogeneity was acceptable, and the fixed effect model of mantel-haenszel method was adopted. Otherwise, the random effect model based on DerSimonian and Laird methods is adopted.

We used Begg funnel plot and Egger's linear regression test to assess potential publication bias. The Egger's linear regression test examines the asymmetry of funnel plot measured on the natural log scale [32]. One-way sensitivity analysis was used to assess which studies had a significant impact on the stability of the results. The OR and 95\% CI were estimated by STATA version 12.0 software (STATA Corporation, College Station, TX). The $P$-value of two-sided $<0.05$ was considered statistically significant.

\section{Results}

\section{Characteristics of eligible studies}

As Fig. 1 shows, the selection process of the studies involved in this meta-analysis was according to PRISMA flow diagram. Firstly, we searched a total of 217 articles from the above databases. Among these, 183 articles were weed out from the retrieval result due to duplicates, irrelevant topics, reviews and not about VDR gene or PCOS. Then, The remaining 34 articles were downloaded underwent full publication review carefully, we removed 21 studies because there was insufficient data to calculate OR and 95\% CI and and it was not a case-control design. Finally, a total of 13 studies were included in this meta-analysis.

The association of the VDR gene ApaI rs7975232 (G > $T)$ polymorphism was examined in 8 case-control studies [15-22] (Table 1), the association of the BsmI rs1544410 $(A>G)$ variant was examined in 8 studies [15-17, 19-23] (Table 2), the association of the Taq1 rs731236 $(T>C)$ variant was examined in 10 studies [14-22, 24] (Table 3), the association of FokI rs $2228570(C>T)$ variant was examined in 7 studies [14-17, 20, 21, 23] (Table 4) andthe association of VDR Tru9I rs 757343 with PCOS susceptibilitywas examined in 3 studies (Table 5).

\section{Meta-analysis results of VDR Apal rs7975232 ( $A>C)$ variant and PCOS susceptibility}

The detailed results of the relationship between $V D R$ gene ApaI rs7975232 $(A>C)$ variant and PCOS susceptibility are shown in Table 6 . A total of 9 studies on the

Table 4 Characteristics of studies on VDR Fokl rs2228570 (C > T) variant and polycystic ovarian syndrome (PCOS) susceptibility

\begin{tabular}{|c|c|c|c|c|c|c|c|c|c|c|c|c|}
\hline \multirow[t]{2}{*}{ Author } & \multirow[t]{2}{*}{ Year } & \multirow[t]{2}{*}{ Country } & \multirow[t]{2}{*}{ Ethnicity } & \multirow{2}{*}{$\begin{array}{l}\text { NOS } \\
\text { scores }\end{array}$} & \multicolumn{2}{|c|}{ Sample size } & \multicolumn{3}{|c|}{ Genotype in cases } & \multicolumn{3}{|c|}{ Genotype in controls } \\
\hline & & & & & PCOS & Control & $\pi$ & $\mathrm{TC}$ & CC & $\pi$ & $\mathrm{TC}$ & CC \\
\hline Dasgupta [14] & 2015 & India & Asian & 7 & 250 & 249 & 8 & 87 & 155 & 9 & 88 & 152 \\
\hline Jedrzejuk [15] & 2015 & Poland & Caucasian & 7 & 90 & 98 & 11 & 51 & 28 & 25 & 50 & 23 \\
\hline Mahmoudi [16] & 2015 & Iran & Asian & 8 & 35 & 35 & 2 & 17 & 16 & 1 & 10 & 24 \\
\hline Mahmoudi [17] & 2009 & Iran & Asian & 8 & 162 & 162 & 12 & 67 & 83 & 7 & 59 & 96 \\
\hline Bagheri [23] & 2012 & Iran & Asian & 7 & 46 & 46 & 22 & 20 & 4 & 29 & 15 & 2 \\
\hline Wehr [20] & 2011 & Australia & Caucasian & 7 & 538 & 135 & 82 & 241 & 215 & 22 & 60 & 53 \\
\hline Cao [21] & 2016 & China & Asian & 7 & 120 & 120 & 10 & 40 & 70 & 10 & 45 & 65 \\
\hline
\end{tabular}


Table 5 Characteristics of studies on VDR Taql rs757343 (G > A) variant and polycystic ovarian syndrome (PCOS) susceptibility

\begin{tabular}{|c|c|c|c|c|c|c|c|c|c|c|c|c|}
\hline \multirow[t]{2}{*}{ Author } & \multirow[t]{2}{*}{ Year } & \multirow[t]{2}{*}{ Country } & \multirow[t]{2}{*}{ Ethnicity } & \multirow{2}{*}{$\begin{array}{l}\text { NOS } \\
\text { scores }\end{array}$} & \multicolumn{2}{|c|}{ Sample size } & \multicolumn{3}{|c|}{ Genotype in cases } & \multicolumn{3}{|c|}{ Genotype in controls } \\
\hline & & & & & PCOS & Control & $\mathrm{AA}$ & $A G$ & GG & $\mathrm{AA}$ & $A G$ & GG \\
\hline Bagheri [23] & 2012 & Iran & Asian & 7 & 181 & 181 & 7 & 51 & 123 & 6 & 48 & 127 \\
\hline Ranjzad [25] & 2012 & Iran & Asian & 8 & 35 & 35 & 1 & 6 & 28 & 0 & 8 & 27 \\
\hline Zadeh-Vakili [26] & 2013 & Iran & Asian & 8 & 221 & 260 & 6 & 58 & 157 & 8 & 66 & 186 \\
\hline
\end{tabular}

relationship between VDR ApaI rs7975232 (A > C) variation and PCOS susceptibility were included. The heterogeneity test demonstrated no significant heterogeneity exist in all studies and the fixed effects model results on Mantel-Haenszel method were used. We found a significant association of the VDR gene ApaI rs7975232 $(A>C)$ polymorphism with PCOS susceptibility in the allelic (C vs. A: $\mathrm{OR}=1.19,95 \% \mathrm{CI}=1.06 \sim 1.34$, $P=0.004)$, recessive $(C C+C A$ vs. $A A: O R=1.20,95 \% C I$ $=1.01 \sim 1.42, P=0.042)$ and dominant $(\mathrm{CC}$ vs. $\mathrm{CA}+\mathrm{AA}$ : $\mathrm{OR}=1.35,95 \% \mathrm{CI}=1.09 \sim 1.69, P=0.008)$ genetic models in the overall populations. Population subgroup analysis showed that there was a significant correlation between VDR ApaI rs7975232 (A > C) polymorphism and PCOS susceptibility in the Asian population (allelic model $\mathrm{C}$ vs. A: $\mathrm{OR}=1.21,95 \% \mathrm{CI}=1.04 \sim 1.42, P=0.016$; dominant model $\mathrm{CC}$ vs. $\mathrm{CA}+\mathrm{AA}: \mathrm{OR}=1.70,95 \% \mathrm{CI}=1.26 \sim 2.29$, $P=0.001$ ) (Fig. 2), but this association was not found in the Caucasian population.

\section{Meta-analysis results of VDR Bsml rs1544410 (A>G) variant and PCOS susceptibility}

In Table 6, a total of 8 studies were included to study the relationship between polymorphism of VDR BsmI rs1544410 $(A>G)$ and PCOS susceptibility. Significant heterogeneity was found in some comparisons and results from the random-effects model using the DerSimonian-Laird method were used. We did not find a correlation between VDR BsmI rs1544410 (A>G) polymorphism and PCOS susceptibility in all genetic models of the general population. Subgroup analysis by ethnicity revealed a significant association between polymorphism of VDR BsmI rs1544410 ( $A>G)$ and susceptibility to polycystic ovary syndrome in the Asian population (allelic model: $\mathrm{G}$ vs. $\mathrm{A}$ : $\mathrm{OR}=1.27,95 \% \mathrm{CI}=$ 1.06 1.53, $P=0.011$; dominant model: GG vs. $\mathrm{CA}+\mathrm{AA}$ : $\mathrm{OR}=1.89,95 \% \mathrm{CI}=1.08 \sim 3.30, \quad P=0.026$ ) (Fig. 2 ), but this association was not found in the Caucasian population.

\section{Meta-analysis results of VDR TaqI rs731236 (T >C) variant and PCOS susceptibility}

In Table 6, 10 studies were included about the relationship between the VDR TaqI rs731236 $(T>C)$ polymorphisms and PCOS susceptibility. Significant heterogeneity was found in most comparisons, and random effects model results on DerSimonian-Laird method were used. We found no correlation between variation and PCOS susceptibility in the general population and in subgroups by ethnicity.

\section{Meta-analysis results of VDR Fokl rs2228570 (C > T) variant and PCOS susceptibility}

Table 6 included 7 studies on the relationship between VDR FokI rs2228570 (C> T) variation and PCOS susceptibility.. The heterogeneity test demonstrated no significant heterogeneity exist in all studies and fixed effects model results on Mantel-Haenszel method were used. There is no association of the VDR FokI rs 2228570 $(C>T)$ variant with PCOS susceptibility was found in the overall population and sub-groups by ethnicity.

\section{Meta-analysis results of VDR Tru9l rs757343 (G > A) variant and PCOS susceptibility}

In Table 6, a total of 3 studies examined the relationship between VDR Tru9I rs757343 (G>A) variation and PCOS susceptibility. The subjects of all included studies were conducted in the Asian populations. The heterogeneity test demonstrated no significant heterogeneity exist in all studies and fixed effects model results on Mantel-Haenszel method were used. There is no association between the VDR Tru9I rs757343 ( $G>A$ ) polymorphism and PCOS susceptibility was found in the Asian population.

\section{Publication bias}

Except for the polymorphism of VDR FokI rs2228570 (C > $\mathrm{T}$ ) and the risk comparison of PCOS in all white genetic models, as these comparisons included only two studies, the Begg and Egger trials were carried out in all comparisons. Begg's funnel plots were performed in all comparisons showed the shape was symmetrical, and the Egger's linear regression analysis further indicated that there was no publication bias in the meta analysis (Table 6, Fig. 3).

\section{Sensitive analysis}

Sensitive analysis was conducted to estimate if our results were substantially affected by the presence of any individual. Our results suggest that no single study has a significant effect on the merger effect (Fig. 4). 


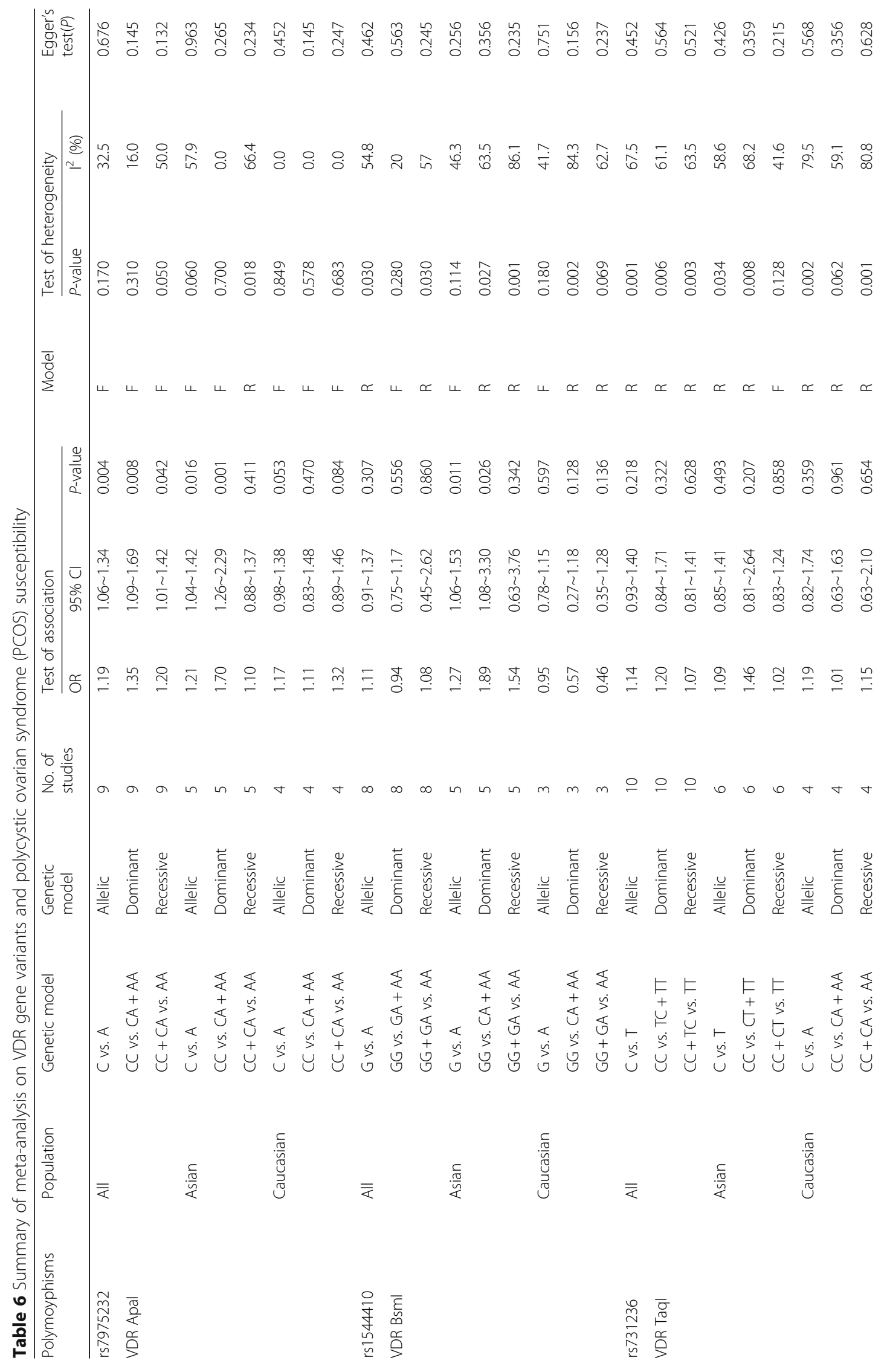




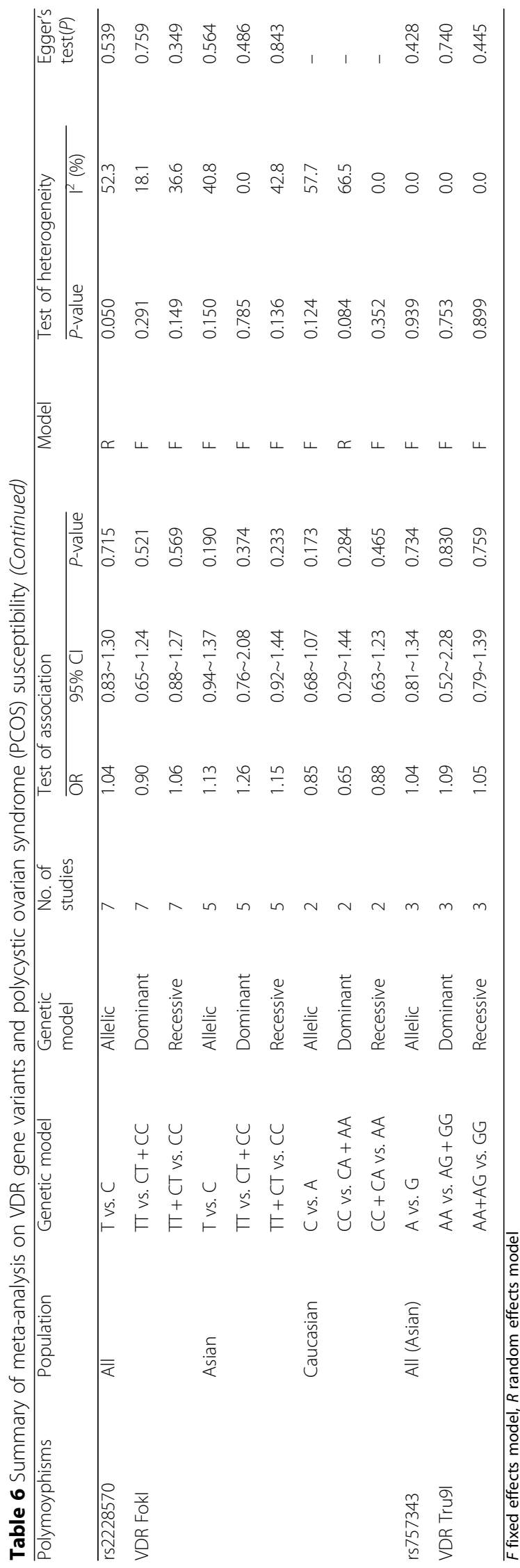




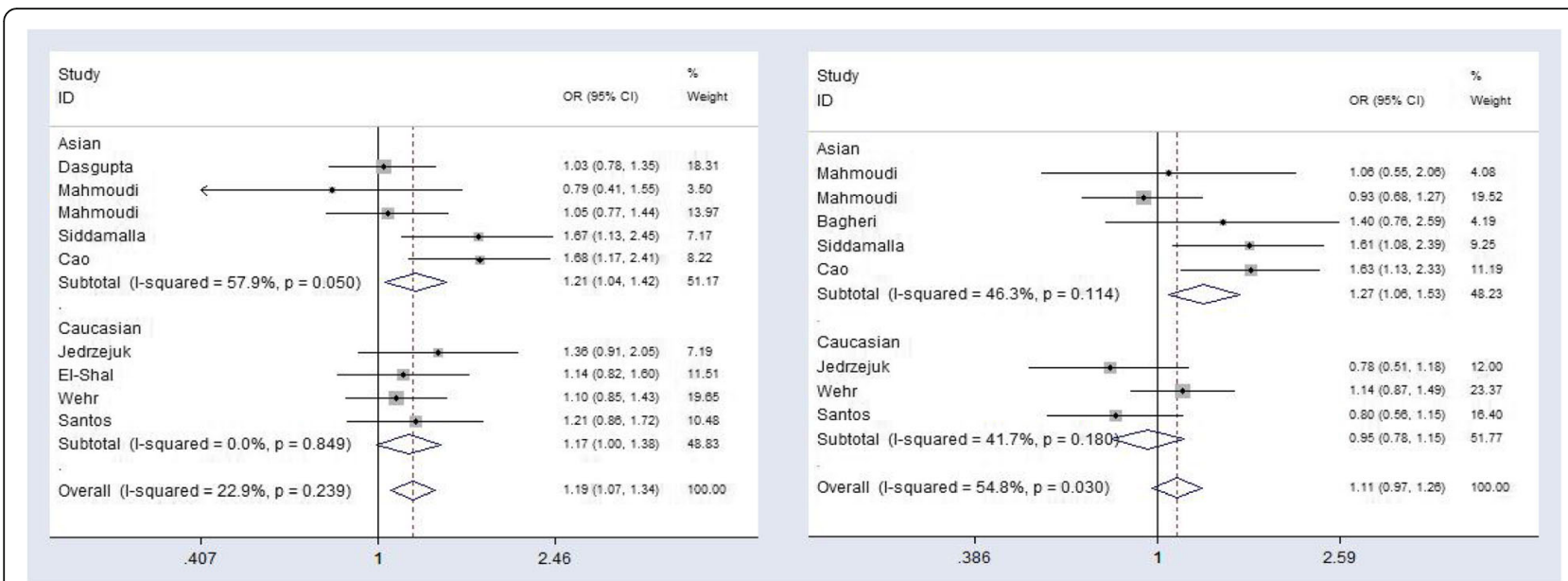

Fig. 2 Forest plots of the VDR polymorphisms and PCOS in the overall populations. VDR Apal (rs7975232) with allelic model: C vs. A; and VDR Bsml (rs1544410) with allelic model: G vs. A

\section{Discussion}

Genetic factors have become increasingly important in the progression of PCOS. Previous studies have shown that $V D R$ gene variants are associated with serum insulin levels in women with PCOS [33]. Serum 25-hydroxyvitamin D $[25(\mathrm{OH}) \mathrm{D}]$ has been shown to have a negative effect on $V D R$-mediated insulin resistance by regulating the expression of target genes [16]. $V D R$ gene involved in insulin signaling pathway is considered as an important candidate gene for PCOS [34]. However, previous genome-wide association studies (GWAS) of Chinese patients with PCOS have not found VDR gene as a new susceptibility site for PCOS [35, 36]. Subsequently, Louwers et al. conducted a cross-racial meta-analysis on the genetic variation of pcos [37].The meta-analysis, which included data from Chinese, US, and Dutch data showed that 12 important variants were mapped to FSHR, LHCGR, SUMO1P1, YAP1, DENND1A, THADA, RAB5B/SUOX, c9orf3 loci, but not included VDR gene [37-39].

In this meta-analysis, we summarized the existing data on the associations of VDR polymorphisms and PCOS susceptibility from available databases. The results included a total of 13 articles based on 1922 PCOS patients and 1665 controls, showed that VDR ApaI (rs7975232) and VDR BsmI (rs1544410) polymorphisms are associated with PCOS susceptibility and VDR TaqI (rs731236), VDR FokI (rs2228570), VDR Tru9I (rs757343) did't reveal a relationship with the PCOS susceptibility. The results were in accordance with previous studies and might provide a new biomarker in the etiology of PCOS $[14,18,20]$. We also performed a subgroup analysis to further explore the potential impact of patient ethnicity on the relationship between $V D R$

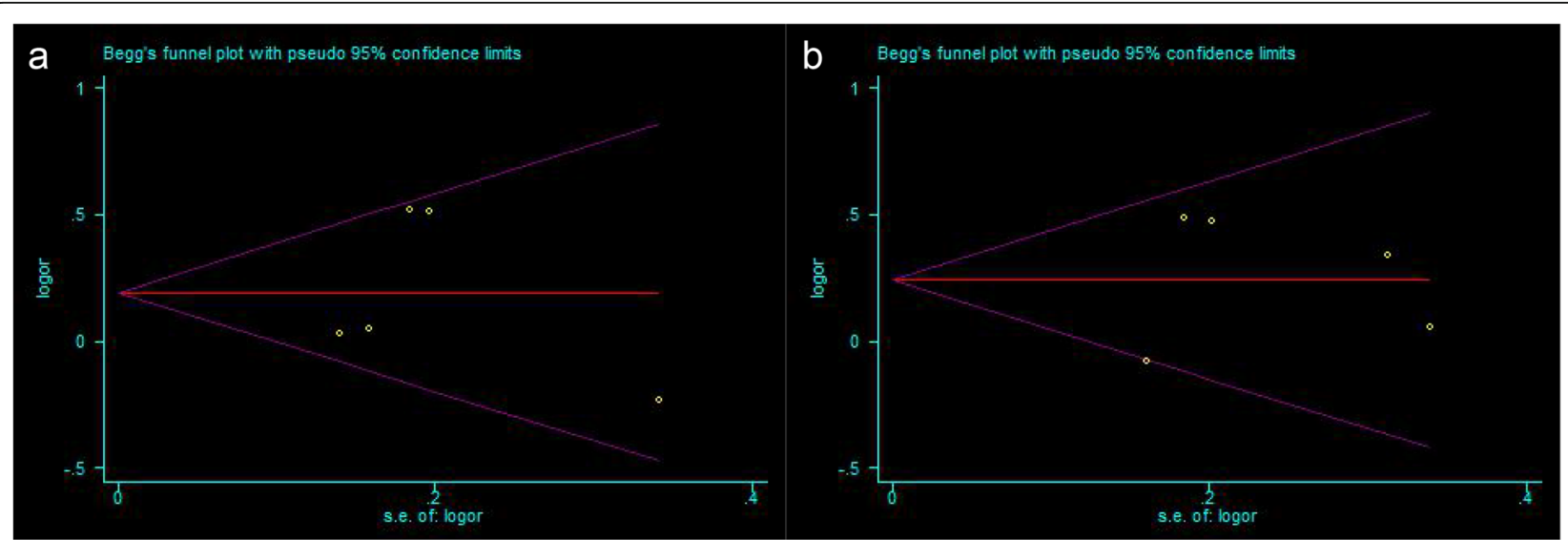

Fig. 3 Begg's funnel plot of the VDR polymorphisms and PCOS in the Asian population. a VDR Apal (r57975232) with allelic model: C vs. A; b VDR Bsml (rs1544410) with allelic model: G vs. A 


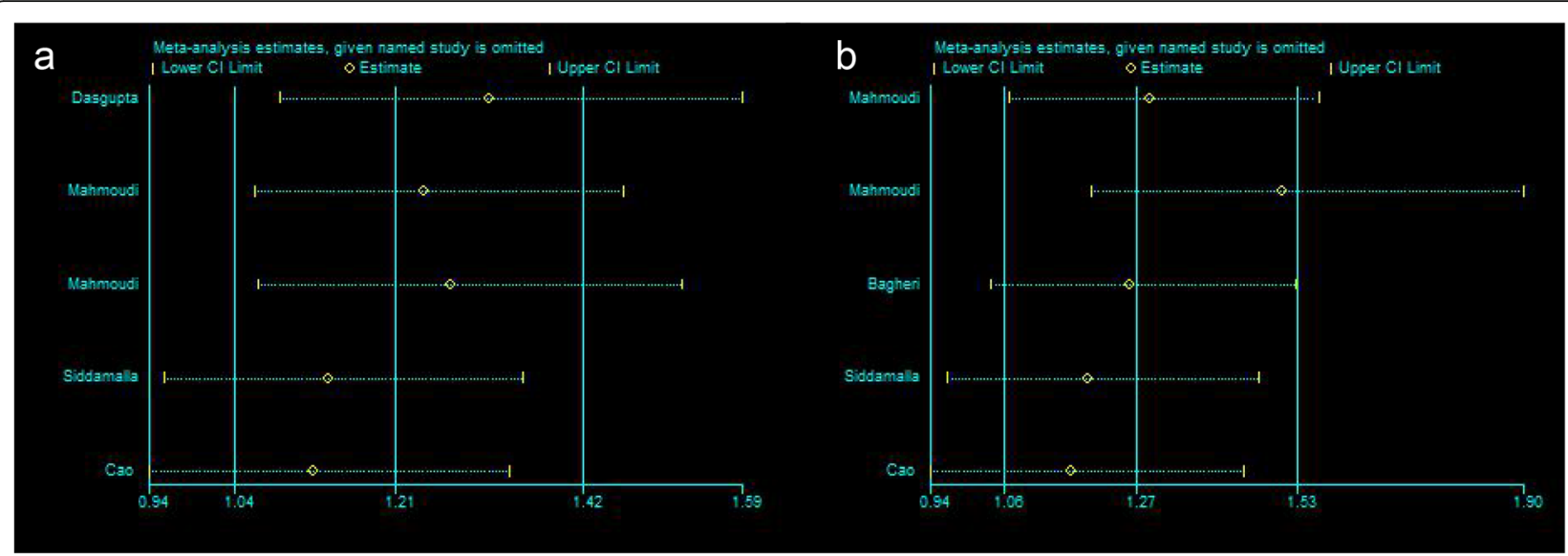

Fig. 4 Sensitive analysis by omitting one study at a time to evaluate the stability of results. a VDR Apal (rs7975232) with allelic model: C vs. A; b VDR Bsml (rs1544410) with allelic model: G vs. A

polymorphisms and PCOS risk. Subgroup analysis by ethnicity showed that VDR ApaI (rs7975232) and VDR BsmI (rs1544410) polymorphisms were significantly correlated with PCOS susceptibility in the Asian population but not in the Caucasian population. The reason for this finding may be genetic disparities between the ethnic groups. Due to the process of natural selection, different groups might have some differences in the functional variants [40].

Accordingly, $V D R$ gene polymorphism may play a role in the pathogenesis of PCOS by affecting the insulin signaling pathway [13]. However, since these polymorphisms are largely nonfunctional, it seems likely that linkage imbalances with another unknown functional variant of the $V D R$ gene would explain the observed association. In addition, $V D R$ gene polymorphism may play a role in the pathogenesis of PCOS by affecting the PTH-vitamin D axis [41]. Consistent with this view, VDR gene polymorphism is associated with serum PTH and $25(\mathrm{OH})$ D levels, and vitamin D-VDR complex inhibits the secretion and synthesis of PTH [42]. Simsek et al. conducted a systematic review suggesting that vitamin $\mathrm{D}$ status is negatively associated with metabolic disorders in PCOS [43]. Next, he demonstrated that serum $25(\mathrm{OH}) \mathrm{D}$ was significantly lower in women with PCOS than in the birth control group. Poor lipids and a high HOMA-IRA were associated with vitamin D status in women with PCOS [44].

The heterogeneity was observed in some comparisons, but partially it was resolved by subgroup analysis based on ethnicity. Our research found that VDR can act as an influencing factor on PCOS. These SNP mutations can be used as risk factors to evaluate PCOS.The results of this meta-analysis were different from those of Han et al. 's previous meta-analysis [27], which showed that VDR gene polymorphism in TaqI (rs731236) for $\mathrm{T}$ allele was significant association with PCOS and didn't find any association between VDR ApaI (rs7975232), VDR BsmI (rs1544410), VDR FokI (rs2228570), VDR Tru9I (rs757343) and PCOS susceptibility in the all included studies. Such inconsistent results may be due to different number of studies included in the meta-analysis, different sample sizes and different statistical abilities. In their study, they conducted a meta-analysis and included 5 (9 studies in the present meta) studies on VDR ApaI rs7975232 $(G>T), 4$ (8 studies in the present meta) studies on VDR BsmI rs1544410 $(A>G), 6$ (10 studies in the present meta) studies on VDR TaqI rs731236 ( $T>$ C), 5 (7 studies in the present meta) studies on $V D R$ FokI rs2228570 $(C>T)$ and didn't include VDR Tru9I rs757343 (G>A) studies (3 in the present meta) for analysis the association with PCOS susceptibility. In addition, we conducted a subgroup analysis by ethnicity among Asian and Caucasian populations, which was not included in their meta-analysis.

Although the present meta-analysis has the advantage of a relatively large sample size for a combined result, several limitations should be addressed in interpreting our results. Firstly, we included relevant articles published only in English and Chinese so that potential language bias may exist in this study. Second, most of the studies were conducted in Asian populations, and the small number of studies in the Caucasian subgroup analysis may have resulted in insufficient statistical ability to detect subtle relationships. Third, age, gender, genetic variation, environmental factors exposure and other risk factors may have an impact on the incidence of PCOS, but this study only considered gene polymorphism. The effects of gene-gene and gene-environment interaction on the occurrence and development of the disease need to be further studied. 


\section{Conclusions}

In summary, current meta-analysis provided statistical evidence that VDR ApaI (rs7975232) and VDR BsmI (rs1544410) polymorphisms are associated with PCOS susceptibility in the Asian population and VDR TaqI (rs731236), VDR FokI (rs2228570), VDR Tru9I (rs757343) did't reveal a relationship with the PCOS susceptibility. These results might not be generalized to other ethnic populations. Further studies with more sample size and including other confounding factors are still needed in the future for a definitive conclusion.

\section{Abbreviations \\ 95\% Cls: 95\% confidence intervals; ORs: Odds ratios; PCOS: Polycystic ovary syndrome; SNP: Single nucleotide polymorphism; VDR: Vitamin D receptor}

\section{Acknowledgements}

Not applicable.

\section{Funding}

There was no funding support in this study.

\section{Availability of data and materials}

All data generated or analyzed during this study are included in this published article.

\section{Authors' contributions}

XYS drafted the manuscript, and together with XLY participated in the design and analyzed the data, APH acquired data, DWX acquired data and helped in writing the manuscript. All authors read and approved the manuscript.

\section{Ethics approval and consent to participate}

Not applicable.

\section{Consent for publication}

Not applicable.

\section{Competing interests}

The authors declare that they have no competing interests.

\section{Publisher's Note}

Springer Nature remains neutral with regard to jurisdictional claims in published maps and institutional affiliations.

\section{Author details}

'Lanzhou University Second Hospital, Medical Record Department, Lanzhou 730030, Gansu Province, China. ${ }^{2}$ Blood Center of Zhejiang Province, Blood Donation Service Department, Hangzhou 310006, Zhejiang Province, China. ${ }^{3}$ Lanzhou University Second Hospital, Intensive Care Unit 2, Lanzhou 730030, Gansu Province, China. ${ }^{4}$ Zhejiang Hospital, Department of nutrition, Hangzhou 310013, Zhejiang Province, China.

Received: 2 November 2018 Accepted: 31 January 2019

Published online: 14 February 2019

\section{References}

1. Dunaif A. Insulin resistance and the polycystic ovary syndrome: mechanism and implications for pathogenesis. Endocr Rev. 1997;18:774-800.

2. Diamanti KE, Kouli CR, Bergiele AT, Filandra FA, Tsianateli TC, Spina GG, et al. A survey of the polycystic ovary syndrome in the Greek island of Lesbos: hormonal and metabolic profie. J Clin Endocrinol Metab. 1999;84:4006-11.

3. Guruvaiah P, Govatati S, Tumu VR, et al. Analysis of Connexin37 gene C1019 T polymorphism and PCOS susceptibility in south Indian population: casecontrol study. Eur J Obstet Gynecol Reprod Biol. 2016;196:17-20.

4. Maitra A, Pingle RR, Menon PS, Naik V, Gokral JS, Meherji PK. Dyslipidemia with particular regard to apolipoprotein profie in association with polycystic ovary syndrome: a study among Indian women. Int J Fertil Womens Med. 2001:46:271-7.

5. Legro RS, Gnatuk CL, Kunselman AR, Dunaif A. Changes in 3 glucose tolerance over time in women with polycystic ovary syndrome: a controlled study. J Clin Endocrinol Metab. 2005;90:3236-42.

6. Diamanti-Kandarakis E, Kandarakis H, Legro RS. The role of genes and environment in the etiology of PCOS. Endocrine. 2006;30:19-26.

7. Wehr E, Moller R, Horejsi R, Giuliani A, Kopera D, Schweighofer N, et al. Subcutaneous adipose tissue topography and metabolic disturbances in polycystic ovary syndrome. Wien Klin Wochenschr. 2009;121:262-9.

8. Thys-Jacobs S, Donovan D, Papadopoulos A, Sarrel P, Bilezikian JP. Vitamin D and calcium dysregulation in the polycystic ovarian syndrome. Steroids. 1999:64(6):430-5.

9. Pittas AG, Lau J, Hu FB, Dawson-Hughes B. Review: the role of vitamin D and calcium in type 2 diabetes. A systematic review and meta-analysis. J Clin Endocrinol Metab. 2007;92:2017-29.

10. Bid HK, Konwar R, Aggarwal CG, et al. Vitamin D receptor (Fokl, Bsml and Taql) gene polymorphisms and type 2 diabetes mellitus: a North Indian study. Indian J Med Sci. 2009;63:187-94.

11. Park BS, Park JS, Lee DY, et al. Vitamin D receptor polymorphism is associated with psoriasis. J Invest Dermatol. 1999:112:113-6.

12. Gyorffy B, Vasarhelyi B, Krikovszky D, et al. Genderspecific association of vitamin $D$ receptor polymorphism combinations with type 1diabetes mellitus. Eur J Endocrinol. 2002;147:803-8.

13. Pittas AG, Lau J, Hu FB, Dawson-Hughes B. The role of vitamin D and calcium in type 2 diabetes. A systematic review and metaanalysis. J Clin Endocrinol Metab. 2007;92:2017-29.

14. Dasgupta S, Dutta J, Annamaneni S, Kudugunti N, Battini MR. Association of vitamin D receptor gene polymorphisms with polycystic ovary syndrome among Indian women. Indian J Med Res. 2015;142(3):276-85.

15. Jedrzejuk D, Łaczmański Ł, Milewicz A, Kuliczkowska-Płaksej J, Lenarcik-Kabza A, Hirnle L, Zaleska-Dorobisz U. Classic PCOS phenotype is not associated with deficiency of endogenous vitamin D and VDR gene polymorphisms rs731236 (Taql), rs7975232 (Apal), rs1544410 (Bsml), rs10735810 (Fokl): a case-control study of lower Silesian women. Gynecol Endocrinol. 2015; 31(12):976-9.

16. Mahmoudi T, Majidzadeh-A K, Farahani H, Mirakhorli M, Dabiri R, Nobakht $H$, Asadi A. Association of vitamin D receptor gene variants with polycystic ovary syndrome: A case control study. Int J Reprod Biomed (Yazd). 2015; 13(12):793-800.

17. Mahmoudi T. Genetic variation in the vitamin D receptor and polycystic ovary syndrome risk. Fertil Steril. 2009;92(4):1381-3.

18. El-Shal AS, Shalaby SM, Aly NM, Rashad NM, Abdelaziz AM. Genetic variation in the vitamin D receptor gene and vitamin D serum levels in Egyptian women with polycystic ovary syndrome. Mol Biol Rep. 2013;40(11):6063-73.

19. Siddamalla S, Reddy TV, Govatati S, Erram N, Deenadayal M, Shivaji S, Bhanoori M. Vitamin D receptor gene polymorphisms and risk of polycystic ovary syndrome in South Indian women. Gynecol Endocrinol. 2018;34(2):161-5.

20. Wehr E, Trummer O, Giuliani A, et al. Vitamin D-associated polymorphisms are related to insulin resistance and vitamin $D$ deficiency in polycystic ovary syndrome. Eur J Endocrinol. 2011;164:741-9.

21. Cao HB, Tu L. Association between vitamin D receptor gene polymorphisms and polycystic ovary syndrome. Pract Clin Med. 2016;17(2):40-2.

22. Santos BR, Lecke SB, Spritzer PM. Apa-I polymorphism in VDR gene is related to metabolic syndrome in polycystic ovary syndrome: a crosssectional study. Reprod Biol Endocrinol. 2018;16(1):38-42.

23. Bagheri M, Rad IA, Jazani NH, Nanbakhsh F. Lack of Association of Vitamin D Receptor Fokl (rs10735810) (C/T) and Bsml (rs1544410) (A/G) Genetic Variations with Polycystic Ovary Syndrome Risk: a Case-control Study from Iranian Azeri Turkish Women. Maedica (Buchar). 2012;7(4):303-8.

24. Bagheri M, Abdi Rad I, Hosseini Jazani N, Nanbakhsh F. Vitamin D Receptor Taql Gene Variant in Exon 9 and Polycystic Ovary Syndrome Risk. Int J Fertil Steril. 2013;7(2):116-21.

25. Ranjzad F, Mahmoudi T, Irani Shemirani A, Mahban A, Nikzamir A, Vahedi M, Ashrafi M, Gourabi H. A common variant in the adiponectin gene and polycystic ovary syndrome risk. Mol Biol Rep. 2012;39(3):2313-9.

26. Zadeh-Vakili A, Ramezani Tehrani F, Daneshpour MS, Zarkesh M, Saadat N, Azizi F. Genetic polymorphism of vitamin D receptor gene affects the phenotype of PCOS. Gene. 2013;515(1):193-6.

27. Han FF, Lv YL, Gong LL, Liu H, Wan ZR, Liu LH. VDR Gene variation and insulin resistance related diseases. Lipids Health Dis. 2017;16(1):157-9. 
28. Rotterdam ESHRE/ASRM-Sponsored PCOS consensus workshop group Revised 2003 consensus on diagnostic criteria and long-term health risks related to polycystic ovary syndrome (PCOS). Hum Reprod. 2004;19(1):41-7.

29. Zawadski JK, Dunaif A. Diagnostic criteria for polycystic ovary syndrome: towards a rational approach. In: Dunaif A, Givens JR, Haseltine FP, Merriam GE, Hershman SM, editors. Polycystic ovary syndrome. Current issues in endocrinology and metabolism. Boston: Blackwell; 1992. p. 377-84.

30. Manoukian S, Stewart S, Dancer S, Graves N, Mason H, McFarland A, Robertson C, Reilly J. Estimating excess length of stay due to healthcareassociated infections: a systematic review and meta-analysis of statistical methodology. J Hosp Infect. 2018; pii: S0195-6701(18)30317-7.

31. Higgins JPT, Thompson SG. Quantifying heterogeneity in a meta-analysis. Stat Med. 2002;21:1539-58.

32. Xiao S, Sun S, Long W, Kuang S, Liu Y, Huang H, Zhou J, Zhou Y, Lu X. A meta-analytic review of the association between two common SNPs in miRNAs and lung cancer susceptibility. Onco Targets Ther. 2018;30(11): 2419-27.

33. Nandi A, Sinha N, Ong E, Sonmez H, Poretsky L. Is there a role for vitamin D in human reproduction? Horm Mol Biol Clin Investig. 2016;25(1):15-28.

34. Shahrokhi SZ, Ghaffari F, Kazerouni F. Role of vitamin D in female reproduction. Clin Chim Acta. 2016;455:33-8.

35. Chen ZJ, Zhao H, He L, et al. Genome-wide association study identifies susceptibility loci for polycystic ovary syndrome on chromosome 2p16.3, 2 p21 and 9q33.3. Nat Genet. 2011:43:55-9.

36. Shi Y, Zhao H, Cao Y, et al. Genome-wide association study identifies eight new risk loci for polycystic ovary syndrome. Nat Genet. 2012:44:1020-5.

37. Louwers $\mathrm{Y}$, Stolk L, Uitterlinden AG, Laven JS. Cross-ethnic meta-analysis of genetic variants for polycystic ovary syndrome. J Clin Endocrinol Metab. 2013;98(12):E2006-12.

38. Goodarzi MO, Jones MR, Li X, et al. Replication of association of DENND1A and THADA variants with polycystic ovary syndrome in European cohorts. J Med Genet. 2012:49:90-5.

39. Welt CK, Styrkarsdottir U, Ehrmann DA, et al. Variants in DENND1A are associated with polycystic ovary syndrome in women of European ancestry. J Clin Endocrinol Metab. 2012;97:E1342-7.

40. Ranjzad F, Mahban A, Shemirani Al, Mahmoudi T, Vahedi M, Nikzamir A, Zali MR. Influence of gene variants related to calcium homeostasis on biochemical parameters of women with polycystic ovary syndrome. J Assist Reprod Genet. 2011;28(3):225-32.

41. Darwish H, DeLuca HF. Vitamin D-regulated gene expression. Crit Rev Eukaryot Gene Expr. 1993;3:89-116.

42. Hollis BW. Circulating 25-hydroxyvitamin D levels indicative of vitamin D sufficiency: implications for establishing a new effective dietary intake recommendation for vitamin D. J Nutr. 2005;135:317-22.

43. Krul-Poel YH, Snackey C, Louwers Y, Lips P, Lambalk CB, Laven JS, Simsek S. The role of vitamin $D$ in metabolic disturbances in polycystic ovary syndrome: a systematic review. Eur J Endocrinol. 2013;169(6):853-65.

44. Krul-Poel YHM, Koenders PP, Steegers-Theunissen RP, Ten Boekel E, Wee MMT, Louwers Y, Lips P, Laven JSE, Simsek S. Vitamin D and metabolic disturbances in polycystic ovary syndrome (PCOS): a cross-sectional study. PLoS One. 2018;13(12):e0204748.

Ready to submit your research? Choose BMC and benefit from:

- fast, convenient online submission

- thorough peer review by experienced researchers in your field

- rapid publication on acceptance

- support for research data, including large and complex data types

- gold Open Access which fosters wider collaboration and increased citations

- maximum visibility for your research: over $100 \mathrm{M}$ website views per year

At BMC, research is always in progress.

Learn more biomedcentral.com/submissions 